\title{
FATORES DE RISCO NO USO DE ANTIMICROBIANOS EM UMA INSTITUIÇÃO HOSPITALAR: REFLEXÓES BIOÉTICAS
}

\begin{abstract}
Tiago Viterbo de Faria ${ }^{1}$, Juliana Dias Reis Pessalacia ${ }^{1}$, Eduardo Sérgio da Silva ${ }^{1}$
Resumo: Estudo descritivo e exploratório, retrospectivo, realizado a partir da coleta em prontuários de pacientes de uma unidade hematológica de um hospital de grande porte do município de Divinópolis, Minas Gerais, Brasil, com o objetivo de identificar fatores de risco no uso de antimicrobianos, no período de janeiro de 2010 a dezembro de 2012. A partir dos fatores identificados, foram propostas reflexóes bioéticas baseadas no princípio da não maleficência, com enfoque para a questão da resistência bacteriana. Identificou-se como fatores de risco, a falta de adoção de medidas de precauçáo conforme o tipo de microorganismos, o uso empírico dos antimicrobianos, a não solicitação de cultura com antibiograma, a falta de adesão aos protocolos institucionais do serviço de controle de infecção e o tempo prolongado de internação hospitalar. Os resultados evidenciaram situaçóes de risco que demonstram o uso irracional de antimicrobianos na instituição estudada, levando a riscos e até mesmo danos aos pacientes e contribuindo para o aumento da resistência bacteriana. Ressalta-se a importância de investimentos em pesquisas e na produção de novos antimicrobianos, entretanto, devem-se adotar medidas de controle e prevenção dos riscos associados à utilizaçáo indevida dos mesmos, conscientizaçáo profissional, institucional e da própria sociedade.
\end{abstract}

Palavras-chave: agentes anti-infecciosos, fatores de risco, bioética, resistência bacteriana

Factores de riesgo en el uso de antimicrobianos en una institución hospitalaria: reflexiones bioéticas

Resumen: Estudio retrospectivo descriptivo y exploratorio, realizado a partir de la recopilación de los registros de pacientes en una unidad de hematología de un hospital en la ciudad de Divinópolis, Minas Gerais, Brasil, con el objetivo de identificar los factores de riesgo en el uso de antimicrobianos en de enero 2010 a diciembre 2012. sobre la base de los factores identificados fueron propuestos reflexiones bioéticas basadas en el principio de no-maleficencia, centrándose en la cuestión de la resistencia bacteriana. Sido identificados como factores de riesgo, la falta de adopción de medidas cautelares de acuerdo al tipo de microorganismos, el uso empírico de antimicrobianos, la no captación de la cultura antibiograma, la falta de adherencia a los protocolos institucionales para el servicio de control de infecciones y hospitalización prolongada. Los resultados mostraron situaciones de riesgo que muestran el uso irracional de los agentes antimicrobianos en la institución estudiada, lo que lleva a los riesgos e incluso dańar a los pacientes y contribuir al aumento de la resistencia bacteriana. Hacemos hincapié en la importancia de la inversión en la investigación y producción de nuevos antibióticos, sin embargo, se debe adoptar medidas de control y prevención de los riesgos asociados con el uso indebido de los mismos, profesional, y la conciencia institucional de la sociedad misma.

Palabras clave: agentes antiinfecciosos, factores de riesgo, bioética, resistencia bacteriana

Risk factors in the use of antimicrobials in a hospital: bioethical reflections

\begin{abstract}
Descriptive and exploratory, retrospective study, conducted from the collection of the records of patients in a hematological unit of a large hospital in the city of Divinópolis, Minas Gerais, Brazil, with the aim of identifying risk factors in the use of antimicrobials in from January 2010 to December 2012. based on the factors identified were proposed bioethical reflections based on the principle of non-maleficence, focusing on the issue of bacterial resistance. Been identified as risk factors, the lack of adoption of precautionary measures according to the type of microorganisms, the empirical use of antimicrobials, the non-solicitation of antibiogram culture, lack of adherence to institutional protocols for infection control service and prolonged hospital stay. The results showed risk situations that demonstrate the irrational use of antimicrobial agents in the institution studied, leading to risks and even damage to patients and contributing to the increase in bacterial resistance. We stress the importance of investment in research and production of new antimicrobials, however, should be adopted control measures and prevention of risks associated with improper use of them, professional, and institutional awareness of society itself.
\end{abstract}

Key words: anti-infective agentes, risk factors, bioethics, drug resistance, bacterial

\footnotetext{
${ }^{1}$ Universidade Federal de São João del Rei (UFSJ), Brasil

Correspondência: juliana@pessalacia.com.br
} 


\section{Introdução}

Os antimicrobianos são compostos naturais ou sintéticos capazes de inibir o crescimento ou causar a morte das bactérias. Eles são produzidos por um conjunto de técnicas que permitem à indústria farmacêutica cultivar microrganismos, por meio da biotecnologia contemporânea(1).

O termo antimicrobiano é abrangente a todas as moléculas de origem natural ou sintética que produzem efeitos inibitórios ou letais em bactérias, fungos e protozoários. Esta ação deve-se a interaçóes com receptores alvo específicos e à indução de respostas bioquímicas, independentemente da origem ou classe do composto(2).

Desde 1950 os antimicrobianos vêm sendo utilizados no tratamento da maioria das doenças infecciosas. Contudo, estudos demonstram evidências da existência de cepas ambientais não patogênicas resistentes a antimicrobianos previamente à sua introdução na prática clínica, demonstram também evidências de que moléculas de baixo peso sempre estiveram presentes no meio ambiente como produtos de metabolismo de alguns microrganismos(2).

Atualmente, a resistência a antimicrobianos em ambientes hospitalares representa uma enorme preocupação, constituindo-se um importante problema de saúde pública(3). Tal resistência, na maioria das vezes, encontra-se associada à utilização indevida destes fármacos, ou seja, de forma não racional(4). Assim, esta problemática vem se constituindo uma ameaça à sociedade e à continuidade da vida humana(5).

É neste contexto que o uso irracional de antimicrobianos e a resistência bacteriana se aproximam da Bioética, considerando-se que tal área de conhecimento preconiza a ética aplicada à análise e reflexão acerca dos fenômenos e situaçóes envolvendo a vida de todos os seres e do planeta, tendo como horizonte a responsabilidade para com as geraçóes atuais e futuras. Ela apresenta e discute questóes que colocam em pauta os valores éticos e morais que devem ser agregados ao desenvolvimento tecnológico e científico nas sociedades, em conjunto com as dimensões humanas e sociais(6).
Considerando-se que o fenômeno da resistência bacteriana não é um problema individual, mas coletivo e mundial(7), destaca-se a importância da análise e reflexáo bioética acerca dos fatores de risco associados ao uso de antimicrobianos em ambientes hospitalares, pois, nos últimos trinta anos, o desenvolvimento destes fármacos diminuiu consideravelmente e, consequentemente, as opçóes para o tratamento de infecçóes causadas por bactérias resistentes estão se tornando cada vez mais limitadas. Os antimicrobianos desenvolvidos atualmente pertencem a classes já existentes e possuem amplo espectro de ação, o que significa que são passíveis de promover o desenvolvimento de resistência, se utilizados inadvertidamente(3).

Portanto, o controle de microrganismos multirresistentes é um tema bioético atual e envolve muitas discussôes devido à crescente evolução da resistência microbiana, seguida do fato de que a indústria farmacêutica não consegue acompanhar a evolução dessa resistência(8). De modo geral, a resistência a antimicrobianos é um problema global e a criaçáo de programas de manejo de antimicrobianos pode ser uma excelente solução(9).

Deste modo, o presente estudo teve como objetivo identificar fatores de risco na utilização de antimicrobianos em uma instituição hospitalar e discutir a questão bioética em torno da relação risco-benefício na utilização de antimicrobianos a partir do princípio bioético da não maleficência, com enfoque para a questão da resistência bacteriana.

\section{Metodologia}

Estudo do tipo descritivo e exploratório, retrospectivo, realizado a partir da análise de prontuários de pacientes da clínica hematológica de um hospital de grande porte do município de Divinópolis, Minas Gerais, Brasil. Foram adotados os seguintes critérios de inclusão: prontuários de pacientes da clínica hematológica que estiveram com infecção bacteriana e que foram tratados com antimicrobianos antes e/ou após a realização da cultura, no período de janeiro de 2010 a dezembro de 2012. Os dados dos prontuários foram coletados a partir de um roteiro de coleta, construído pelos pesquisadores a partir de dados encontrados na literatura acerca de situaçóes de 
risco no uso de antimicrobianos em instituiçôes hospitalares. Inicialmente este instrumento foi testado em uma amostra aleatória de 106 (cento e seis) prontuários, visando verificar a adequaçáo, pertinência ou insuficiência dos itens a serem coletados. O roteiro sofreu pequenas alteraçôes, visando o seu aprimoramento. Antes de iniciar a coleta de dados, o projeto de pesquisa foi submetido à análise pelo Comitê de Ética em Pesquisa da instituição proponente, recebendo o número de aprovação No 138188. Por se tratar de pesquisa retrospectiva, foi solicitada a dispensa do termo de consentimento livre e esclarecido (TCLE), garantindo-se, entretanto, o compromisso com o sigilo e a confidencialidade dos dados. Posteriormente, procedeu-se a coleta de dados na amostra total e os dados coletados foram organizados e submetidos à análise estatística através do aplicativo IBM/SPSS 19.0. As variáveis qualitativas foram descritas em forma de tabelas e gráficos para melhor visualização. Para as variáveis quantitativas, foi verificada a normalidade dos dados coletados através do teste Kolmorogov-Smirnov e assim submetidos à análise estatística utilizando-se o teste $t$ de student para correlacionar as variáveis quantitativas de maior interesse pela correlação de Pearson ou para comparação de médias. Para os dados que não apresentaram normalidade, foi utilizada a correlação de Spearman. As associaçóes entre as variáveis categóricas foram testadas pelo teste do Qui-Quadrado de independência. O nível de significância estabelecido para todas as análises foi de $5 \%$. Os fatores de riscos identificados foram discutidos tomando como base o princípio bioético da não maleficência descrito no Modelo Principialista de Tom Beauchamp e James Childress, a partir da obra Princípios de ética biomédica, publicada inicialmente em 1979 e traduzida no Brasil em 2002. Nesta obra, estão descritos os princípios da Autonomia, Justiça, Beneficência e da Não maleficência. O princípio da Não maleficência adotado como referencial neste estudo, prevê a identificação, prevenção ou mesmo extinção de riscos $(10)$.

\section{Resultados}

A partir dos critérios adotados, foram incluídos duzentos e setenta e cinco $(275 ; 100 \%)$ prontuários de pacientes em tratamento com antimicrobianos.
Sobre o tipo de acomodação dos pacientes, duzentos e setenta e um (271) estavam alocados em acomodação Comum $(98,5 \%)$ e apenas quatro em acomodaçáo de Precaução (1,5\%), sendo que, três deles com patógenos transmissíveis multirresistentes. Os quartos de precaução poderiam ser do tipo: precaução de contato, precaução respiratória ou precaução de contato e respiratória. Cabe ressaltar que foram identificados microrganismos com perfil de resistência em três dos quatro pacientes acomodados em quartos de precaução, sendo dois (2; 50,0\%) Staphylococcus aureus e um (1; 25,0\%) Klebsiella pneumonae. Os demais pacientes acometidos pelos patógenos identificados neste estudo (ver Tabela 1) não foram alocados em quartos de precaução, inclusive um paciente com Acinetobacter baunanii sensível apenas à Polimixina B.

Quanto ao tipo de antimicrobiano utilizado, segundo o espectro de açáo, identificaram-se quarenta e dois $(42 ; 15,3 \%)$ gram + s, noventa e dois $(92 ; 33,5 \%)$ gram -s, vinte e dois $(22 ; 8 \%)$ anaerobicidas, duzentos e sessenta e sete $(267 ; 97,1 \%)$ de amplo espectro e dezenove (19; 6,9\%) antifúngicos.

A maioria dos pacientes utilizou uma terapêutica combinada com dois ou mais antimicrobianos, sendo dos duzentos e setenta e cinco (275) pacientes estudados duzentos e vinte e três (223), ou seja, oitenta e um por cento $(81,1 \%)$, utilizaram terapia combinada. Portanto, nota-se uma prevalência na utilização de antimicrobianos de amplo espectro $(267 ; 97,1 \%)$ e uma terapêutica combinada $(223 ; 81,1 \%)$.

Observou-se que dos 275 (100\%) prontuários pesquisados, foram realizados exames de cultura em apenas 158 (64,7\%) deles. Entretanto, os resultados analisados demonstram a presença de bactérias multirresistentes conforme descrito na Tabela 1. Uma informação importante, identificada a partir da análise não sistematizada de alguns prontuários, foi a questáo da morosidade na obtenção dos resultados dos exames de cultura. Para ilustrar esta situação, cabe ressaltar que identificou-se um prontuário em que o paciente estava hospitalizado com infecção do trato urinário por Klebsiella pneumonae, e não foi prescrito a este paciente nenhum tipo de antimicrobiano durante o 
Fatores de risco no uso de antimicrobianos em uma instituição hospitalar - Tiago Viterbo de Faria et al.

Tabela 1: Tipo de patógenos identificados a partir de resultados de exames de cultura realizados em pacientes em uso de antimicrobianos no período de janeiro de 2010 a dezembro de 2012, Divinópolis, Minas Gerais, Brasil, 2014.

\begin{tabular}{|l|r|r|}
\hline Tipos de Patógenos & $\mathrm{N}$ & $(\%)$ \\
\hline Acinetobacter baumani & 5 & 9,8 \\
\hline Bastonetes gram-negativos & 1 & 2 \\
\hline Candida albicans & 1 & 2 \\
\hline Candida parapsilosis & 1 & 2 \\
\hline Cocos gram-positivos & 1 & 2 \\
\hline Enterobacter aerogenes & 1 & 2 \\
\hline Enterobacter aerogenes/ Enteroc. faecalis & 1 & 2 \\
\hline Enterobacter cloacae & 6 & 11,5 \\
\hline Enterobactercloacae/ Escherichia coli/ Staphylococcus epidermidis & 1 & 2 \\
\hline Enterobacter gergovial/ Enteroc. faecalis & 1 & 2 \\
\hline Enterococcus faecium & 1 & 2 \\
\hline Escherichia coli & 9 & 17,5 \\
\hline Klebsiella pneumonae & 2 & 3,9 \\
\hline Pseudomonas aer./ Enterococcus faecalis & 1 & 2 \\
\hline Pseudomonas aeruginosa & 1 & 2 \\
\hline Staphylococcus aureus & & \\
\hline Staphylococcus epidermidis/ Enterobacter cloacae & 3 & 5,8 \\
\hline Staphylococcus epidermidis & 1 & 2 \\
\hline Staphylococcus hominis & 51 & 100 \\
\hline Staphylococcus copitis & 7 & 13,7 \\
\hline Staphylococcus hemolyticus & 3 & 5,8 \\
\hline Estreptococcus pneumonae & 1 & 2 \\
\hline Estreptococcus plurenimalum & 1 & 2 \\
\hline Total & 1 \\
\hline
\end{tabular}

Tabela 2: Correlação entre a Análise de Cultura com a troca de antimicrobianos obtidos das variáveis qualitativas, no período de janeiro de 2010 a dezembro de 2012, Divinópolis, 2014.

\begin{tabular}{|c|c|c|c|c|c|c|}
\hline \multirow{2}{*}{ Análise de Cultura } & \multicolumn{4}{|c|}{ Troca de antimicrobiano } & \multirow[b]{2}{*}{ Total } & \multirow[b]{2}{*}{ Valor de $(\mathrm{P})^{*}$} \\
\hline & Não & $\%$ & Sim & $\%$ & & \\
\hline Não & 105 & 38,2 & 12 & 4,4 & 117 & \\
\hline Sim & 71 & 25,8 & 87 & 31,6 & 158 & $<0,001$ \\
\hline Total & 176 & & 99 & & 275 & \\
\hline
\end{tabular}

* obtido pelo teste do Qui-Quadrado de Independência.

Teste do Qui-Quadrado com correção de continuidade de Yates.

período de internação, pois o exame de cultura ficou pronto após sua alta hospitalar.

A tabela 1 apresenta os tipos de patógenos identificados em cento e cinquenta e oito $(158 ; 100 \%)$ exames de cultura realizados, onde cinquenta e um $(51 ; 32,3 \%)$ tiveram resultados positivos.
Nos cento e cinquenta e oito $(158 ; 100 \%)$ prontuários que foram submetidos a procedimentos de cultura, oitenta e sete $(87 ; 55,1 \%)$ trocaram o antimicrobiano. No entanto, quando se analisa os cento e dezessete $(117 ; 74,1 \%)$ prontuários em que não foram realizados os procedimentos de cultura, apenas doze $(12 ; 7,6 \%)$ trocaram de antimicrobianos, como demonstra a tabela 2. 
Também se identificou que dos 275 (100\%) prontuários analisados houve intervenção do Serviço de Controle de Infecção Hospitalar (SCIH) em noventa e seis $(96 ; 34,9 \%)$. E, dos prontuários em que houve este tipo de intervenção, foi feita a troca de antimicrobianos em cinquenta e seis (56; $58,3 \%)$ deles. Adicionalmente, quando não houve intervenção do serviço, ou seja, em cento e setenta e nove $(179 ; 65,1 \%)$ prontuários, na maioria deles $(136 ; 75,9 \%)$ não foi realizada troca de antimicrobianos, como demonstra a tabela abaixo.

A tabela 3 mostra a correlação entre a intervenção do $\mathrm{SCIH}$, com a troca de antimicrobianos obtidos das variáveis qualitativas.

Neste estudo, dos 53 exames de cultura positivas, identificou-se que foram realizados antibiogramas de todas, exceto nos Bastonetes Gram- e Cocos Gram +. Foi possível perceber no perfil do antibiograma das culturas positivas, a existência de cepas multirresistentes como é o caso a maioria dos Staphylococcus sp. Já o patógeno Acinetobacter baunanii foi sensível apenas as Polimixinas. A klebsiella pneumonae mostrou-se resistente à maioria dos antimicrobianos testados estando sensível ao meropenem (Amplo espectro), Amicacina e Piperaciclina. Cabe ressaltar também, que oito (8; 15,7\%) Staphylococcus epidermidis foram resistentes a Penicilina e a Oxacilina (meticilina), e por último apenas duas $(2 ; 3,9 \%)$ Escherichia coli mostrou resistência, sendo uma a Gentamicina e outra a Amicacina.
O tempo de permanência dos pacientes submetidos ao tratamento com antimicrobianos analisados foi obtido através da subtração da data de internação com a data de alta mais um. O tempo de permanência mostrou que a maioria esteve de 1 a 18 dias, o tempo mínimo de 01 dia e o tempo máximo acima de 48 dias. Quanto ao tempo de tratamento com antimicrobianos, identificou-se que a maioria esteve utilizando antimicrobianos por um período entre 1 a 16 dias, sobressaindo o período entre 1 a 12 dias.

\section{Discussão}

Observa-se a partir dos resultados apresentados que na maioria dos prontuários pesquisados, os pacientes em tratamento com antimicrobianos se encontravam, desde o início do tratamento, em acomodaçóes comuns. Entretanto, vários destes pacientes estavam acometidos por bactérias multirresistentes e transmissíveis (ver Tabela 1), as quais demandavam adoção de medidas de precaução e isolamento específicas a fim de evitar a propagaçáo destes microorganismos a outros pacientes internados. Portanto, a falta de adoção de medidas de precaução conforme o tipo de microorganismos foi uma situação de risco identificada neste estudo, pelo fato de terem sido identificados vários outros agentes infecciosos a partir dos resultados de exames de cultura, mas apenas quatro pacientes terem sido alocados em quartos de precaução.

Sabe-se que a falta de adesão às medidas de precaução pode acarretar como consequência o au-

Tabela 3: Correlação entre a intervenção do Serviço Controle Infecção Hospitalar (S.C.I.H.), com a troca de antimicrobianos obtidos das variáveis qualitativas, no período de janeiro de 2010 a dezembro de 2012, Divinópolis, Minas Gerais, Brasil, 2014.

\begin{tabular}{|c|c|c|c|c|c|c|}
\hline \multirow{2}{*}{ Intervenção do S.C.I.H. } & \multicolumn{5}{|c|}{ Troca de antimicrobiano } & \multirow[b]{2}{*}{ Valor de $(\mathrm{P})^{*}$} \\
\hline & Não & $(\%)$ & $\operatorname{Sim}$ & $(\%)$ & Total & \\
\hline Não & 136 & 49,4 & 43 & 15,7 & 179 & \\
\hline Sim & 40 & 14,5 & 56 & 20,4 & 96 & $<0,001$ \\
\hline Total & 176 & & 99 & & 275 & \\
\hline
\end{tabular}

* Obtido pelo teste do Qui-Quadrado de Independência. Teste do Qui-Quadrado com correção de continuidade de Yates. 
mento do índice de transmissão cruzada e o aumento dos custos com os antimicrobianos(11). Assim, considerando-se o princípio da não maleficência, ressalta-se a importância da conscientização profissional na adoção destas medidas, visando com isto, à redução dos riscos e danos a pacientes hospitalizados e a disseminação de microorganismos(7).

Apesas de o princípio da não maleficência ter sobressaído na situação de risco identificada, cabe ressaltar a importância de se considerar o princípio bioético da justiça, à medida que, esta questão também pode envolver o problema bioético da alocação de recursos escassos em saúde. $\mathrm{O}$ problema em questão encontra-se no fato de que a necessidade de alocar um paciente acometido com um patógeno multirresistente em um único quarto poderia culminar na falta de leitos para a acomodação de outros pacientes.

Outra questão bioética presente neste contexto é a questão do preconceito e do desconforto relacionados à adoção de medidas de precauçáo. Para a adoção destas medidas, faz-se necessário, em alguns casos, a restriçáo da liberdade de indivíduos (pacientes) e a utilização de barreiras para proteção, visando impedir a disseminação de determinado microorganismos(11) e, esta ideia de que pacientes devam ficar isolados do convívio de outras pessoas pode proporcionar sentimentos de constrangimento ou vergonha por parte dos mesmos e de seus familiares. Também podem estar sujeitos a preconceitos por parte de acompanhantes dos demais pacientes, pois receiam adquirir a enfermidade. Neste sentido, ressalta-se a importância de a adoção de medidas de precauçáo e isolamento virem acompanhadas de esclarecimentos aos pacientes que estarão sujeitos às medidas, seus acompanhantes e pacientes alocados em acomodaçôes próximas, prevenindo-se, assim, o estigma e o preconceito(12).

Outra situação de risco identificada foi o uso de antimicrobianos de amplo espectro e de forma empírica, conforme resultados apresentados. $\mathrm{O}$ tratamento empírico pode ser evidenciado pelo fato de todos os pacientes terem sido tratados com pelo menos um antimicrobiano, mas, entretanto, apenas cinquenta e um $(51 ; 18,5 \%)$ estarem comprovadamente com algum tipo de patógeno.
Ou seja, os outros duzentos e vinte e quatro (224; $81,4 \%)$ pacientes, faziam uso de antimicrobianos sem nenhuma infecção comprovada.

A prescrição de antimicrobianos em ambientes hospitalares se baseia, primeiramente, na efetividade do medicamento. Vários estudos demonstram que uma terapia empírica agressiva de amplo espectro e precoce se correlacionam com melhores desfechos(13). Por outro lado, o uso desnecessário de antimicrobianos de amplo espectro aumenta a chance de surgimento de bactérias resistentes nestes ambientes(14).

Neste contexto o princípio da não maleficência remete à questão do uso racional de antimicrobianos em instituiçóes hospitalares, o qual se propóe a oferecer um equilíbrio entre a terapia de amplo espectro e o risco de resistência bacteriana. $\mathrm{O}$ problema bioético se encontra na questão envolvendo o uso de uma terapêutica desnecessária em detrimento à necessidade de adoção de medidas profiláticas. Também se pode citar o problema bioético da alocação de recursos em saúde, onde o uso de uma terapêutica desnecessária poderia proporcionar maiores custos para o sistema de saúde.

Assim, o uso racional de antimicrobianos envolveria a prescrição destes fármacos a partir da confirmação laboratorial, destacando-se o método de cultura. Neste estudo identificou-se que em cento e cinquenta e oito $(158 ; 100 \%)$ prontuários que foram submetidos a procedimentos de cultura, oitenta e sete $(87 ; 55,1 \%)$ foram submetidos à troca do antimicrobiano. Este resultado confirma importância deste procedimento no contexto do uso racional dos antimicrobianos, pois, quando se analisa os cento e dezessete $(117 ; 74,1 \%)$ prontuários em que não foram realizados os procedimentos de cultura apenas doze $(12 ; 7,6 \%)$ trocaram de antimicrobianos, como demonstrou a tabela 2 .

Portanto, o ideal seria a solicitação de exames microbiológicos para a identificação dos patógenos, antes de iniciar a terapêutica. Contudo, esta medida ainda levantaria um dilema em torno do conflito existente entre a necessidade da aplicação de recursos na compra de determinados medicamentos para o tratamento de pacientes (açáa curativa) em detrimento ao investimento na com- 
pra de equipamentos para exames de diagnósticos (ação preventiva) (11).

Nesta situação, o princípio da não maleficência se sobressai novamente, pois se sabe que a solicitação dos exames microbiológicos está relacionada à prescrição do antimicrobiano adequado e, consequentemente, à diminuição dos riscos aos pacientes e à sociedade. Neste sentido, o investimento nestes exames se justificaria pelo custo-benefício relacionado à redução dos impactos referentes às complicaçóes clínicas e sequelas associadas às infecções hospitalares e à diminuição da resistência bacteriana em ambientes hospitalares.

A solicitação do exame de cultura para a identificação do microrganismo causador de infecção hospitalar é um procedimento padronizado na maioria dos $\mathrm{SCIH}$ e também no serviço da instituição pesquisada, podendo ser um instrumento útil para a intervenção do referido serviço nas terapêuticas hospitalares com antimicrobianos. Também são estabelecidos protocolos voltados para a identificação do tipo de antimicrobiano mais adequado segundo o microrganismo. Contudo, observa-se que, muitas vezes, os profissionais não se atentam para as disposiçôes destes protocolos, ocasionando riscos aos pacientes e à sociedade, à medida que, contribuem para o aumento da resistência bacteriana.

Portanto, outro fator de risco identificado neste estudo foi a falta de adesão aos protocolos institucionais do $\mathrm{SCIH}$, à medida que, a solicitação de cultura encontrava-se como procedimento recomendado no protocolo do serviço na instituição de estudo, entretanto, tal procedimento foi adotado em apenas 158 (64,7\%) prontuários de pacientes em tratamento com antimicrobianos.

Observou-se ainda, que as intervenções do citado serviço foram determinantes para a troca de antimicrobianos, pois em noventa e seis (96; $34,9 \%$ ) prontuários em que houve intervenção do mesmo, foi feita a troca de antimicrobianos em cinquenta e seis $(56 ; 58,3 \%)$ deles. Adicionalmente, quando não houve intervenção do referido serviço, ou seja, em cento e setenta e nove $(179 ; 65,1 \%)$ prontuários, na maioria deles (136; $75,9 \%$ ) não foi realizada troca de antimicrobianos, como demonstra a Tabela 3.
Portanto, ressalta-se a importância das açóes do SCIH no controle de infecçóes hospitalares e da resistência bacteriana. Enfatiza-se também a necessidade de co-responsabilização de todas as pessoas envolvidas no contexto destas práticas, ou seja, gestores, profissionais de saúde, usuários e familiares, enfim a sociedade, de forma a qualificar a atenção nas instituiçóes que prestam assistência à saúde(15).

Assim, nota-se o quanto este serviço é importante para o controle de infecçóes e da resistência bacteriana, entretanto, muitas instituiçóes hospitalares ainda não atentam para a contribuição deste serviço na assessoria administrativa da instituição, diagnosticando e vigiando a frequência e a distribuição das infecções hospitalares e intervindo através da implantaçáo e/ou implementação de medidas de controle que visam garantir a qualidade e segurança da sua assistência(15).

Contudo, cabe destacar que falta de adesão aos protocolos do SCIH no que tange à solicitação de exames de cultura também pode estar relacionada às condiçóes estruturais dos laboratórios hospitalares. No presente estudo, foi identificada uma morosidade na divulgação dos resultados dos exames laboratoriais. Quanto a isto, cabe ressaltar que, o sucesso dos programas de controle de infecção hospitalar depende do envolvimento ativo do laboratório de microbiologia. Os resultados dos exames laboratoriais devem estar disponíveis de modo prático e rápido, a fim de poderem ser consultados pelo corpo clínico do hospital(16). Além disso, a investigação precoce e precisa de multirresistência de microrganismos em ambiente hospitalar poderia ter impacto na redução da morbimortalidade. Neste sentido, a demora na liberação dos resultados de exames microbiológicos fere ao princípio da não maleficência, por proporcionar riscos importantes aos pacientes(17). No entanto, esta situação ainda envolve uma questão bioética em torno do princípio da justiça, considerando-se que esta morosidade pode estar relacionada à alta demanda, qualificação insuficiente e aparelhagem defasada nos laboratórios.

Portanto, em decorrência da grande incidência de infecçóes hospitalares por microrganismos multirresistentes nos últimos anos, faz-se necessária a capacitação dos laboratórios de microbiologia na 
detecção e comunicação rápida de resultados obtidos, a fim de que medidas adequadas de controle e isolamento sejam estabelecidas pelo $\mathrm{SCIH}$, para evitar a disseminação destes microrganismos(18).

É recomendado ainda, que o uso de um antimicrobiano seja posterior à realização de um antibiograma para racionalizar o uso dos medicamentos, justificando que a não identificação do perfil de resistência do patógeno a antimicrobianos pode ocasionar maior toxicidade e contribuir para a seleção de microorganismos resistentes(19). Portanto, a adoção da cultura com antibiograma, seria uma medida importante na diminuição da resistência bacteriana nos contexto das instituições hospitalares. Neste estudo, foram realizados antibiogramas em todos os exames de cultura, sendo identificados perfis de resistência em vários microrganismos.

Apesar de não ter sido identificada relação estatística significante entre as variáveis tempo prolongado de internaçâo e uso indevido de antimicrobianos, o tempo prolongado também pode ser considerado fator de risco, pois o mesmo poderia ser relacionado ao atraso na liberaçáo dos resultados dos exames de cultura ou às alteraçóes no tempo de uso de antimicrobianos decorrente de prescriçōes indevidas. O tempo de duração da terapia com antimicrobianos é definido pelo organismo causador e o sítio de infecção. A maioria das infecçóes de corrente sanguínea, pneumonias e infecçôes de partes moles necessita de 10 a 14 dias de tratamento. Recomenda-se que os antimicrobianos sejam mantidos pelo menos até que haja sinais de recuperação medular e o paciente esteja afebril por no mínimo $24 \mathrm{hs}(20)$.

Cabe ressaltar, que o uso de antimicrobianos de forma inapropriada também está associado ao aumento de reaçóes adversas aos pacientes e, estas também constituem um fator relacionado ao aumento do tempo de internação(21). Portanto, o tempo prolongado em um leito hospitalar, seja por motivo de atraso na liberação dos resultados dos exames de cultura, seja por alteraçóes no tempo de uso de antimicrobianos decorrente de prescrição indevida, oferece aos pacientes riscos adicionais, por isso, infringem o princípio da não maleficência, mesmo que de forma não intencional. Ao contrário disto, a unidade hospitalar deveria proporcionar benefícios para os pacientes que nela se encontram, sendo concebida como um instrumento de cura e a distribuição de seu espaço torna-se um instrumento terapêutico(22).

\section{Conclusôes}

No presente estudo, foram identificadas situações de risco relacionadas às práticas de utilização de antimicrobianos em uma instituição hospitalar. Associado às situaçóes identificadas, a partir da análise de resultados de exame, foram encontrados microrganismos resistentes. Tais riscos foram discutidos a partir do princípio bioético da não maleficência, sendo propostas medidas de precaução e minimização para os mesmos.

Assim, o princípio bioético da não maleficência, o qual considera as obrigaçóes de não ocasionar e de prevenir danos, foi adotado como referencial no contexto desta pesquisa, pois se entende que a falta de adoção de medidas de prevenção de riscos e danos decorrentes da utilização indevida de antimicrobianos em isntituições hospitalares tem provocado o aumento da resistência bacteriana.

Portanto, ressalta-se a importância de investimentos em pesquisas e na produçáo de novos fármacos, entretanto, com maior controle e prevenção dos riscos associados à utilização indevida, com ênfase na conscientização profissional, institucional e da própria sociedade.

A partir de uma análise sistêmica a respeito das questôes bioéticas em torno da utilização de antimicrobianos em instituiçóes hospitalares, conclui-se que são as práticas de má utilização destes fármacos que têm impulsionado o aumento da resistência bacteriana e náo o aumento da produção e comercialização dos mesmos. Entretanto, foi ressaltada, conjuntamente, a necessidade de adoção de medidas de precaução e prevenção quanto aos riscos identificados, enfatizando-se a importância da capacitação profissional, investimento e reconhecimento das açóes do $\mathrm{SCIH}$ e da conscientização profissional e da sociedade em geral quanto aos riscos do uso irracional destes fármacos.

Vale ainda destacar que as situaçóes de risco identificadas, também apontam para outras questóes 
bioéticas importantes, tais como a falta de acomodaçóes suficientes e adequadas para a adoção de medidas de precaução e controle e de laboratórios equipados e com profissionais capacitados para a identificação de agentes microbiológicos.
A falta de estrutura institucional contribui para o aumento da resistência bacteriana, à medida que dificulta o cumprimento dos protocolos do SCIH e, consequentemente, a acessibilidade a tratamentos de qualidade, o que remete ao princípio bioético da justiça.

\section{Referências}

1. Guimarães DO, Momesso LS, Pupo MT. Antimicrobianos: importância terapêutica e perspectivas para a descoberta e desenvolvimento de novos agentes. Quim Nova 2010; 33(3): 667-669.

2. Davies J, Davies D. Origins and evolution of antibiotic resistance. Microbiol Mol Biol Rev 2010; 74(3): $417-433$.

3. Doron S, Davidson LE. Antimicrobial stewardship. Mayo Clin Proc 2011; 86(11): 1113-1123.

4. Levy SB, Marshall B. Antibacterial resistance worldwide: causes, challenges and responses. Nat med 2004; 10(1): 122129.

5. Andrade D, Leopoldo VC, Haas VJ. Ocorrência de bactérias multiresistentes em um centro de terapia intensiva de hospital brasileiro de emergências. Rev Bras Ter Intensiva 2006; 18(1): 27-33.

6. Carvalho RRP, Fortes PAC, Garrafa VA. Saúde suplementar em perspectiva bioética. Rev Assoc Med Bras 2013; 59(6): $600-606$.

7. Santos NQ. A resistência bacteriana no contexto da infecção hospitalar. Texto contexto - enferm (online) 2004; 13: 64-70.

8. Askarian M, Afkhamzadeh R, Monabbati A, Daxboeck F, Assadian O. Risk factors for rectal colonization with vancomycin-resistant enterococci in shiraz. Int J Infect Dis 2008; 12(2): 171-175.

9. Goff DA, Bauer KA, Mangino JE. Antimicrobial stewardship management of infections: beyond the costs of antimicrobials. Pharmacy Practice News 2012; 39:1-12.

10. Beauchamp TL, Childress JF. Princípios da ética biomédica. 2a ed. São Paulo: Loyola; 2002.

11. Cavalcante NJF. Ética e controle de infecção hospitalar. Rev Bioét 2009; 4(2).

12. Rabelo AHS, Souza TV. O conhecimento do familiar/acompanhante acerca da precauçáo de contato: contribuiçóes para a enfermagem pediátrica. Rev Esc Anna Nery 2009;13(2): 271-278.

13. Marra AR, Almeida SM, Correa L, Silva MJR, Martino MD, Silva CV. The effect of limiting antimicrobial therapy duration on antimicrobial resistance in the critical care setting. Am J Infect Control 2009; 37(3): 204-209.

14. Reis HPLC, Vieira JBM, Sartori DP, Fonseca DP, Viana DB, Cunha JM, et al. Avaliação da resistência microbiana em hospitais privados de Fortaleza-Ceará. Rev Bras Farm 2013; 94(1): 83-87.

15. Oliveira R, Maruyama S. Controle de infecção hospitalar: histórico e papel do estado. Rev Eletr Enf 2008; 10(3): 775-783.

16. Oliveira AC, Gonzaga C, Costa R, Damaceno QS, Garbaccio JL. Desafios e perspectivas para a contençáo da resistência bacteriana na óptica dos profissionais de saúde. Rev Eletr Enf2013; 15(3): 747-754.

17. Guimarães AC, Donalisio MR, Santiago THR, Freire JB. Óbitos associados à infecção hospitalar, ocorridos em um hospital geral de Sumaré-SP, Brasil. Rev Bras Enferm 2011; 64(5): 864-869.

18. Moraes GM, Cohrs FM, Batista REA, Grinbaum RS. Infecção ou colonização por micro-organismos resistentes: identificação de preditores. Acta Paul Enferm 2013; 26(2): 185-191.

19. Maier CR, Abegg MA. Avaliação da utilização de antimicrobianos por profissionais de saúde e pela população na cidade de Toledo, Paraná, Brasil. Arq Ciênc Saúde UNIPAR 2007; 11(1): 19-26.

20. Freifeld AG, Bow EJ, Sepkowitz KA, Boeckh MJ, Ito JI, Mullen CA, et al. Infectious Diseases Society of America. Clinical practice guideline for the use of antimicrobial agents in neutropenic patients with cancer: 2010 update by the Infectious Diseases Society of America. Clin Infect Dis 2011; 52(4): 56-93.

21. Nicolini PN, Jorge WL, Greco KV, Menezes FG. Fatores relacionados à prescrição médica de antibióticos em farmácia pública da região oeste da cidade de São Paulo. Ciênc Saúde Coletiva 2008; 13(supl): 689-696.

22. Silva HB. Beneficência e paternalismo médico. Rev Bras Saúde Matern Infant 2010; 10(2): 419-425.

Recebido: 29 de julho de 2014

Aceito: 11 de agosto de 2014 